\title{
State of Stresses: How to Simulate it Correctly in the Lab?
} Vamegh Rasouli*

Vamegh Rasouli, Associate Professor, Petroleum Engineering Department, Curtin University, Australia

The state of stresses is significantly important in terms of its impact on oil and gas upstream activities. From practical point of view three principal stresses are assumed in a field. The vertical stress is due to the weight of overburden rocks. As the rocks are constrained in their movement underground horizontal stresses will be imposed to an element of rock: this is related to the vertical stress and its magnitude is a function of formation properties. The horizontal stress is unlikely to be equal in different directions due to the existence of fractures at different scales and different geological structures such as folds or anticlines. Therefore it is anticipated that the horizontal stress is maximum in one specific direction, perpendicular to which the minimum horizontal stress acts in the same plane. This is while most of the lab experiments, such as hydraulic fracturing and sanding studies are carried out on cylindrical shaped samples where horizontal stresses are identical: this is contrary to the real state of stresses as applies to the rock. To correctly perform lab experiments a cube of rock is to be used to which three independent stresses can be applied.

As an example, let's consider drilling in a highly stressed field, e.g. a faulty region. In this situation high stress anisotropy is expected to be experienced and this would significantly vary depending on the geometry of the drilled well with respect to the fault planes. The principal stresses are likely to change their orders as the well advances: this means that the stress regime may change, for example, from normal to strike-slip with respect to depth. Having an understanding about this is very important in terms of choosing the optimum drilling of directional wells in the nearby areas. In general, and with the objective of mitigating instability of the wellbore it is recognised that drilling along the minimum stress direction is the best in a normal stress regime. The change in stress regime will also have a direct impact on hydraulic fracturing operation. An induced fracture tends to propagate along the maximum stress direction. Change in stress regime potentially means that the direction of fracture propagation may be different at different depths.

The above discussion demonstrates the necessity of using a true triaxial stress cell (for example see Rasouli and Evans, 2010) for lab simulations of various petroleum related applications such as hydraulic fracturing. Design and operation of such an apparatus may well be more expensive and complex than customarily used triaxial cells. However, for advanced simulations it is highly advisable to accept the use of such an equipment in the lab as this could potentially save a large amount of costs by providing even little information which may help in a better well design.

\section{Reference}

1. Rasouli, Evans J B (2010) A True Triaxial Stress Cell (TTSC) to simulate deep downhole drilling conditions J APPEA 50: 61-70
*Corresponding author: Vamegh Rasouli, Associate Professor, Petroleum Engineering Department, Curtin University, Australia, E-mail: V.Rasouli@curtin.edu.au

Received October 19, 2011; Accepted November 16, 2011; Published November 18, 2011

Citation: Rasouli V (2011) State of Stresses: How to Simulate it Correctly in the Lab? J Pet Environ Biotechnol 2:e103. doi:10.4172/2157-7463.1000e103

Copyright: () 2011 Rasouli V. This is an open-access article distributed under the terms of the Creative Commons Attribution License, which permits unrestricted use, distribution, and reproduction in any medium, provided the original author and source are credited. 